\title{
Frio Brine Sequestration Pilot in the Texas Gulf Coast
}

GCCC Digital Publication Series \#03-01

\author{
Susan D. Hovorka \\ Paul R. Knox
}

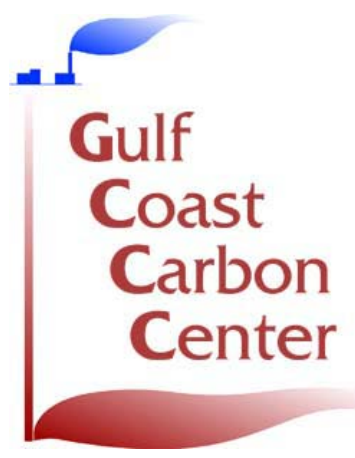

Keywords:

Frio Brine Pilot Experiment- Overview, Geologic Sequestration- Brine Formations

\section{Cited as:}

Hovorka, S. D., and Knox, P. R., 2003, Frio brine sequestration pilot in the Texas Gulf Coast, in Gale, J., and Kaya, Y., Greenhouse gas control technologies: Proceedings, 6th International Conference on Greenhouse Gas Control Technologies, October 1-4, Kyoto, Japan: New York, Pergamon, p. 583-587. GCCC Digital Publication Series \#03-01. 


\title{
I1-2
}

\section{FRIO BRINE SEQUESTRATION PILOT IN THE TEXAS GULF COAST}

\author{
Susan D. Hovorka and Paul R. Knox \\ Bureau of Economic Geology, John A. and Katherine G. Jackson School of Geosciences, The \\ University of Texas at Austin, Box X, Austin TX 78713-8924 USA, (512) 471-4863, \\ susan.hovorka@beg.utexas.edu
}

\begin{abstract}
A field experiment to pioneer $\mathrm{CO}_{2}$ injection for sequestration in a brine-bearing sandstoneshale sequence in the Texas Gulf Coast, USA, is in the preinjection modeling and planning phase. Innovations in this experiment include (1) $\mathrm{CO}_{2}$ injection into high-volume highpermeability rocks that have storage capacity sufficient to impact greenhouse gas emissions, (2) injection into a setting lacking the complications introduced by hydrocarbons and perturbations resulting from production and secondary recovery, and (3) intensive pre-, syn-, and post-injection monitoring and modeling for validation of the effectiveness of sequestration. The experiment is designed to provide a rapid increase in information from a small-volume and short-duration injection.
\end{abstract}

\section{INTRODUCTION}

Brine-bearing formations below and hydrologically separated from potable water have been widely recognized as having high potential for very long term (geologic time scale) sequestration of greenhouse gases, particularly the large volumes of $\mathrm{CO}_{2}$ resulting from combustion or generation of hydrogen from fossil fuels. Numerous feasibility and modeling studies document the potential for this type of disposal; however, no site isolated from the complexities introduced by hydrocarbon production is currently available where basic field experiments to confirm model results and demonstrate feasibility can be conducted.

The purpose of the project described here is to develop a suitable site and conduct initial experiments. We have designed a project that will quickly produce information and experience by (1) recycling existing infrastructure, (2) building on known technologies and regulatory processes for deep-well waste disposal and $\mathrm{CO}_{2}$-enhanced oil recovery $\left(\mathrm{CO}_{2}\right.$-EOR), (3) selecting a geologically isolated injection site suitable for experiments with small volumes of injected $\mathrm{CO}_{2}$ without risk of impact to adjacent properties, and (4) building on the earlier phase of our projects and of the GEOSEQ project. This site complements and extends the results of other planned and ongoing sequestration experiments in EOR settings or future 
large-scale settings by providing a site for initial experiments in a typical high-injectivity sandstone area of high emissions.

\section{GOALS}

We established four main goals for the project: (1) demonstrate that $\mathrm{CO}_{2}$ can be injected into a saline formation without adverse health, safety, or environmental effects, (2) determine the subsurface location and distribution of the $\mathrm{CO}_{2}$ cloud, (3) demonstrate understanding of conceptual models, and (4) develop experience necessary for success of future large-scale $\mathrm{CO}_{2}$ injection experiments. In order to assure that this first onshore experiment is positive, we will meet regulatory requirements, design well completions to assure control injection into the target horizon, and monitor to document the absence of impact on the environment, associated hydrocarbon production, or induced seismicity. In additional, we will assess the long-term fate of the injected $\mathrm{CO}_{2}$ in the subsurface in terms of rate of flux back to the atmosphere.

\section{METHODS}

This project demonstrates the processes of sequestration in a brine formation setting in the location where very large scale sequestration may be needed to significantly offset anthropogenic $\mathrm{CO}_{2}$ releases. On the basis of the results from our previous study [1] we determined that the optimal target for this demonstration is the Frio Formation in the area of Houston, Texas, USA (fig. 1). Advantages of this setting are (1) large volumes of $\mathrm{CO}_{2}$ are currently released from power generation and industrial sources, (2) numerous high-injectivity sandstones can serve as injection targets, and numerous thick shales will serve as seals, (3) abundant geologic and geotechnical data are available, and (4) infrastructure is well developed, including many inactive wells and easy and low-cost access to needed support for field operations.

The Bureau of Economic Geology at The University of Texas at Austin is leading a research team to create an onshore U.S. $\mathrm{CO}_{2}$ sequestration field demonstration in a brine formation setting. The selected site is in Liberty County northeast of Houston, Texas. Texas American Resources Company, our field partner, is providing access to several idle wells in a 50-yearold oil field that will be recompleted in a nonproductive Frio sandstone interval. $\mathrm{CO}_{2}$ will be trucked to the site and injected into a high-permeability upper Frio sandstone. Sandia Technologies and Transpetco will provide waste and $\mathrm{CO}_{2}$ injection expertise. Team partners from the GEOSEQ project, including researchers from Lawrence Berkeley National Lab, Lawrence Livermore National Lab, and Oak Ridge National Lab, will conduct a series of field monitoring experiments before, during, and after $\mathrm{CO}_{2}$ injection. These experiments will test the effectiveness of a spectrum of $\mathrm{CO}_{2}$ monitoring techniques and compare results to validate the methods.

The project includes a planning phase, preinjection field activities, injection experiments, postproject synthesis, reporting, technology transfer, and stakeholder involvement. Planning phase characterization and modeling are currently under way. Permitting and preinjection field activities, including well workovers, recompletions, hydrologic characterization of the injection interval, and baseline preinjection monitoring, will begin during late 2002. Injection will be completed within 100 days, followed by a year of monitoring and assessment. 


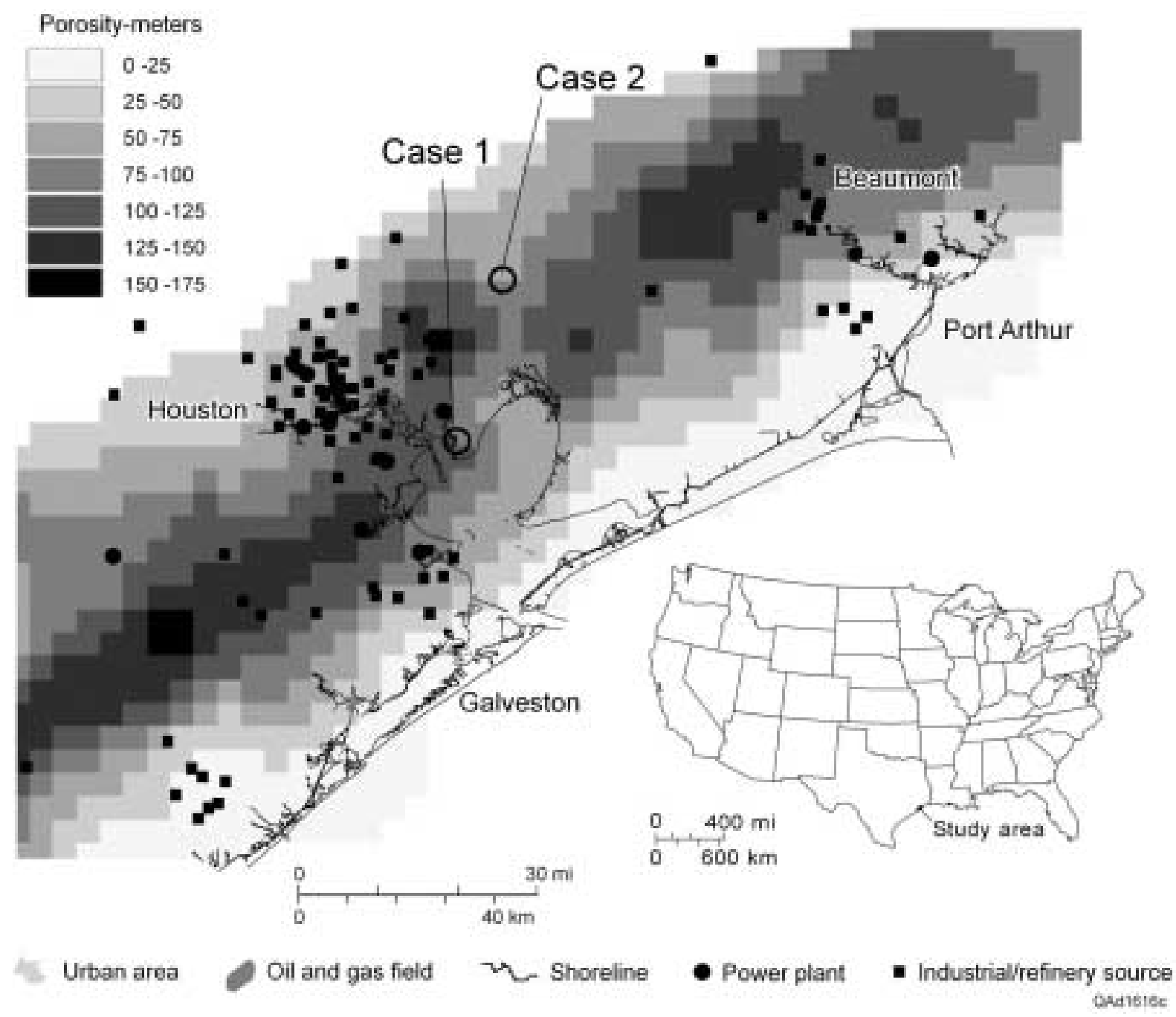

Figure 1: Within a 7-county area $\left(16,700 \mathrm{~km}^{2}\right)$ centered on Houston, Texas, 10 power plants released an estimated 32 million metric tons of $\mathrm{CO}_{2}$ in 1996. In addition, more than 100 chemical manufacturing plants and refineries in the same area continue to release an unknown additional volume of $\mathrm{CO}_{2}$. Directly beneath most of these emitters are high-capacity sandstones that are most likely a suitable site for sequestration of $\mathrm{CO}_{2}$.

The study site provides for a rapid start-up using existing infrastructure and low risk of adverse impacts because the injection will be made into a hydrologically isolated reservoir compartment of a well-known geologic structure. Injection will occur in the Frio Formation beneath the thick Anahuac shale (fig. 2), and lateral migration of $\mathrm{CO}_{2}$ will be limited by structural compartmentalization along faulting associated with the setting on the flank of a salt dome. Idle wells will be recompleted in a brine-bearing interval $1,000 \mathrm{~m}$ above the oil reservoir. A small volume of $\mathrm{CO}_{2}$ will be trucked to the site and injected into a 10 -m-thick transmissive sandstone. An updip well will also be completed for monitoring $\mathrm{CO}_{2}$ migration. Response will be monitored both within the injection sandstone bed and in overlying thin sandstone separated from the injection sandstone by a few meters of shale. Safety is implicit in the experiment design, which is focused on intensive monitoring. Additional safety will be provided by using contractors experienced in $\mathrm{CO}_{2}$ injection and hazardous waste disposal. An existing 3-D seismic survey and wireline well logs are providing input data for planning phase modeling. Extensive field-scale data, brine chemistry, and core available for the Frio Formation in the region are being collected and used to guide the study. 


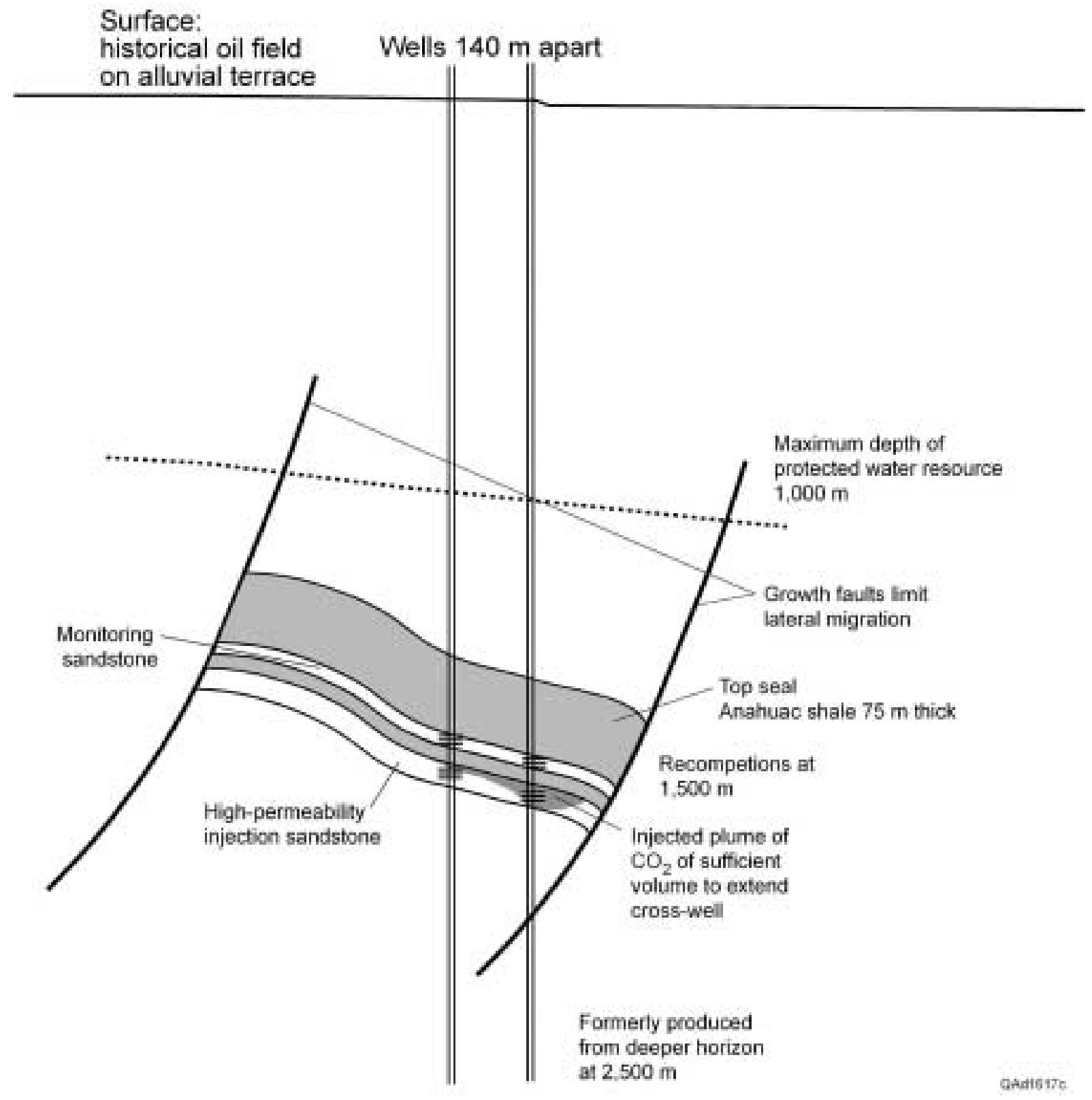

Figure 2: The experiment will use a fault compartment adjacent to a salt dome to limit the potential for $\mathrm{CO}_{2}$ escape.

Analytical tools being evaluated for use include construction of a geologic and geotechnical database and 3-D realization; modeling of plume geometry using TOUGH2 code [2, 3]; pressure buildup and falloff analysis of data collected in the injection and observation wells; single-well, crosswell, tomographic, and crosswell downhole seismic imaging to characterize the injection interval and to monitor plume geometry; electrical resistance tomography (ERT) to monitor plume geometry; downhole logging; reactive transport modeling; assessment of compartmentalization from production history; monitoring $\mathrm{CO}_{2}$ phases with natural stable isotopes; monitoring using introduced tracers $\mathrm{SF}_{6}$, perfluorocarbons (or PFC's), and noble gases; modeling of geophysical response; and geochemical modeling. 


\section{PROGRESS}

Planning-phase characterization has been completed. Data include analysis of a $49-\mathrm{km}^{2} 3-\mathrm{D}$ seismic survey, interpretation of 37 well logs, and interpolation of petrophysical characteristics from regionally equivalent oil fields. Hydrologic characterization will be completed after workovers. A 3-D geotechnical model has been created, first in a generalized and simplified version, Version 0 , and then in a realistically controlled revised model, Version 1. Modeling is currently under way to design the experiment and prepare documents for permitting. The injection will be permitted as a Class 5 experimental well because of the small volume, short duration, and research purpose of the well.

\section{RESULTS}

Texas is the lead state in U.S. $\mathrm{CO}_{2}$ emissions, and in the Gulf Coast many of the emitters directly overlie unused high-volume, high-injectivity brine-bearing sandstones that are prospective targets for geologic sequestration because they are isolated from potable water by thick, regionally extensive shales. This small-volume, short-duration project will demonstrate feasibility of geologic sequestration in this setting as a mechanism for emissions reduction. Successful completion of the project will provide experience in permitting, characterizing, modeling, injection, monitoring, and validation of geologic sequestration. We intend that the results will lead to development of full-scale sequestration projects that combine using $\mathrm{CO}_{2}$ for EOR, enhanced gas recovery, sequestration at abandonment, and using large volumes available in associated brine strata to meet emission-reduction targets.

\section{ACKNOWLEDGMENTS}

This project is funded by the U.S. Department of Energy National Energy Technology Laboratory under contract No. DE-AC03-76SF000098.

\section{REFERENCES CITED}

1. Hovorka, S. D., Romero, M. L., Warne, A. G., Ambrose, W. A., Tremblay, T. A., Treviño, R. H., and Sasson, D. (2000). Sequestration of greenhouse gases in brine formations, http://www/beg.utexas.edu/ $\mathrm{CO}_{2} /$.

2. Pruess, K., and Garcia, J. (in press). Env. Geol.

3. Pruess, K., Oldenburg, C., and Moridis, G. (1999). TOUGH2 user's guide, version 2.0: Berkeley, CA, Lawrence Berkeley National Laboratory Report LBNL-43134, November. 